\title{
Theoretical calculations of the relative pKa values of some selected aromatic arsonic acids in water using density functional theory
}

\author{
Behzad Khalili $^{\mathbf{a}^{*}}$ and Mehdi Rimaz
}

${ }^{a}$ Department of Chemistry, Faculty of Siences, University of Guilan, P.O. Box 41335-1914, Rasht, Iran

${ }^{b}$ Department of Chemistry, Payame Noor University, P.O. Box 19395-3697, Tehran, Iran

\section{H R O N I C L E}

Article history:

Received July 21, 2015

Received in revised form

August 29, 2015

Accepted 8 October 2015

Available online

8 October 2015

Keywords:

Arylarsonic acid

Relative pKa

DFT study

Aqueous media

\begin{abstract}
A B S T R A C T
With the focus on calculating the equilibrium constant (Ka) of arsonic acids ( $\left.\mathrm{RAsO}(\mathrm{OH})_{2}\right)$ in aqueous media, the behavior of both neutral and negatively charged species of some arsonic acids have been considered through the isodesmic reaction scheme with polarized continuum model of solvation. The relative pKa values of a number of arsonic acids were calculated using density functional theory (DFT), with methylarsonic acid $\left(\mathrm{CH}_{3} \mathrm{AsO}(\mathrm{OH})_{2}\right)$ used as a reference molecule. Various basis sets such as $(6-31 G(d), 6-31+G(d), 6-311++G(d, p)$ and 6$311++G(2 d, 2 p))$ in conjunction with B3LYP computational method were examined. Finally the latter one was found to give better results. The results of applied B3LYP 6-311++G(2d,2p) method for pKa values of 25 arsonic acids in aqueous media showed good agreement with corresponding experimental pKa values. In this level of theory the average error was less than $0.3 \mathrm{pKa}$ units. The type of substituent affected the acid strength, with electron withdrawing substituents lowering the $\mathrm{pKa}$ and electron releasing groups increasing it.
\end{abstract}

\section{Introduction}

Arsonic acids have the general formula of $\mathrm{RAs}(\mathrm{O})(\mathrm{OH})_{2}$ in which R could be alkyl or aryl group. Organo arsenic compounds despite their toxicity gets revived attention due to pharmaceutical use. ${ }^{1-4}$ For example Carbarsone is an organoarsenic compound with antiprotozoal activity which is used against of the amebiasis. ${ }^{5-7}$ They also are under consideration from the biological activity point of view yet. $^{8-10}$

Organo arsenic compounds are very useful starting materials with important application in various fields of chemistry. For example Lloyd et al used the aryl arsonic acids as precursors to As(III) and As(I) species as part of their studies into the chemistry and biological activity of Salvarsan which is the historically-important arsenical drug for treatment of syphilis. ${ }^{11-12}$

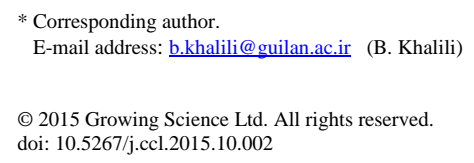


In addition some of the aryl arsonic acids have own application, for example 3-nitro-4-hydroxyphenyl arsonic acid (Roxarsone), 3-nitrophenyl arsonic acid (Nitarsone) and 4-aminophenyl arsonic acid (Arsanilic acid) are aryl arsonic acid derivatives which are produced commercially on a large scale.

Roxarsone, Nitarsone and Arsanilic acid are growth promoter for poultry, and were used as a feed additive to increase weight gain and improve feed efficiency in poultry production. ${ }^{13}$ They also used as an animal drug in poultry. For example controlling of Histomoniasis is possible only by Nitarsone ${ }^{14}$ and Arsanilic acid used to prevent or treat dysentery in poultry and swine. ${ }^{13}$

Finally aryl arsonic acids can be used as an indicator for determining metal ions among other uses. For instance Miller ${ }^{15}$ reports use of arsanilic acid for detection of cerium. Due to importance and wide range application of arsenic compounds it seems that we need for more research work about them. The goal of this work is determining of the pKa value as a criterion for acidity power of aryl arsonic acids. We hope that our reported results in this work could be helpful for other researchers who try to understand more about arsenic compounds behavior in biological systems and etc.

The pKa value for a compound, defined as the negative logarithm of the dissociation constant of the acid $(-\operatorname{logKa})$, plays an important role in understanding a number of phenomena in different scientific domains including life sciences, chemistry and material sciences. The pKa is the most important characteristic for comparing the acidity of a series of compounds. ${ }^{16-19}$ The pKa value also indicates the ratio of neutral and anionic forms of a molecule at a given $\mathrm{pH} .{ }^{20}$ The large number of papers describing computational research on the prediction of the acidity of various compounds in the recently published chemical literature indicates that the $\mathrm{pKa}$ is one of the important properties in many scientific domains such as chemistry and biology. ${ }^{19,21}$ For example, determining the acidity of some ionizable groups could be helpful in understanding its role at the molecular level in some biologically active molecules. $^{22}$

The experimental determination of pKa values in reaction intermediates, specific parts of large biological building blocks, and molecules with dissolution limitations is very difficult to obtain. ${ }^{18,19,23}$ In addition, providing standard conditions for the experimental determination of pKa value is essential for allowing comparison of different results. Accordingly, many researchers are tending to calculation of pKa values using theoretical and computational approaches. ${ }^{21,24-41}$

Recently quantum chemical calculations, using thermodynamical parameters such as Gibbs free energy, have reported good correlations between calculated and experimental acidities of a wide range of organic and inorganic acids. ${ }^{18,42-50}$ For example, gas phase and solution phase acidities of some organic compounds investigated by Namazian et al. and Kheirjou et al. reported good correlation between ab initio calculations of pKa values with the experimental data. ${ }^{19,21,51-52}$ However, to the best of our knowledge, there is no data on pKa calculations of arsonic acids by quantum chemical methods, and experimentally determined pKa values are limited to a small group of arsonic acid derivatives.

Accordingly, we have calculated the relative pKa values of some of aryl arsonic acids using using the DFT/B3LYP approach in conjunction with some selected basis sets such as (6-31G(d), 6-31+G(d), 6$311++G(d, p)$ and $6-311++G(2 d, 2 p))$. Our results showed good agreement between theoretical values and experimental results, especially using the B3LYP/6-311++G(2d,2p) method for calculation; the average error was less than 0.8 when using B3LYP/6-311++G(d,p), and 0.3 when using B3LYP/6$311++G(2 d, 2 p)$ level of theory.

\section{Methods and theoretical calculations}

First of all for choosing the best basis set with the minimum average of error we calculate pka values of three of arsonic acids (phenyl arsenic acid, 2-methoxyphenyl arsenic acid and 3-nitrophenyl arsenic acids ) using various selected basis sets. The results collected on Table 1. 
As appears from the results of Table 1 the best basis set for our goal is the $6-311++G(2 d, 2 p)$ which is resulted $\mathrm{pKa}$ values with lower difference from the experimental values. In the case of 6-31G(d) basis set in some cases we have approximately more than one unit(1.72) difference between experimental and calculated pKa values whereas with 6-311++G(2d,2p) basis set we can reduce this differences below 0.25 unit. Therefor the $6-311++\mathrm{G}(2 \mathrm{~d}, 2 \mathrm{p})$ basis set gives more accurate and reliable results than 6-31G(d) one. In continue we applied both of the B3LYP/6-311++G(d,p) and B3LYP/6$311++G(2 d, 2 p)$ levels for pKa calculation.

Table 1. Results of pKa calculation using various basis sets.

\begin{tabular}{cccccc}
\hline \multicolumn{5}{c}{ Calculated pKa $(\Delta \mathbf{p K a})$} \\
\hline Basis Set & $6-311++\mathrm{G}$ & $6-311++\mathrm{G}$ & $6-31 \mathrm{G}$ & $6-31+\mathrm{G}$ & $\begin{array}{c}\text { Exp. } \\
\end{array}$ \\
$(\mathrm{d}, \mathrm{p})$ & $(2 \mathrm{~d}, 2 \mathrm{p})$ & $(\mathrm{d})$ & $(\mathrm{d})$ & $\mathrm{pKa}$ \\
\hline $\begin{array}{c}\text { Phenyl } \\
\text { arsonic acid }\end{array}$ & $2.91(0.56)$ & $3.34(0.13)$ & $2.27(1.19)$ & $2.55(0.92)$ & 3.47 \\
2-methoxyphenyl & $3.11(0.97)$ & $3.89(0.19)$ & $2.33(1.75)$ & $3.29(0.78)$ & 4.08 \\
arsonic acid & & & & \\
3-nitrophenyl & $1.60(1.26)$ & $2.63(0.23)$ & $2.86(1.61)$ & $1.14(1.72)$ & 2.86 \\
arsonic acid & & & & \\
\hline
\end{tabular}

Initially the calculations for the arsonic acids and their conjugate anions were fully optimized at B3LYP/6-311++G(d,p) level of theory. Vibrational frequency calculations were done at the same level to verify that each stationary point was a real minimum. All calculations were performed using the GAMESS program package. ${ }^{53}$

The polarized continuum model (PCM) was used for acquiring data in the solution phase. The solution phase optimization of both neutral and anionic species was performed at the B3LYP/6-311++G(d,p) level on the structures obtained from gas phase optimizations. Natural bond orbital (NBO) analysis was also used to reveal the charge distribution in neutral and deprotonated structures.

The calculation of the pKa value for an acid undergoing dissociation can be carried out using the change of Gibbs free energy for the dissociation reaction as shown below, where HA represents the arsonic acid.

$$
\begin{aligned}
& H A_{(a q)}+H_{2} O_{(a q)} \stackrel{\Delta G^{0}}{\longrightarrow} A^{-}{ }_{(a q)}+H_{3} O^{+}{ }_{(a q)} \\
& \Delta G^{0}=-2.303 R T \log \left(\mathrm{Ka} /\left[\mathrm{H}_{2} \mathrm{O}\right]\right)
\end{aligned}
$$

or

$$
\Delta G^{0}(\mathrm{kcal} / \mathrm{mol})=1.36 \mathrm{pKa}+2.36
$$

Eq. (3) simply relates the equilibrium constant and changes of Gibbs free energy of dissociation process to each other. In this equation $\Delta \mathrm{G}^{0}$ is the standard change in the Gibbs free energy related to the dissociation process taking place at $298.15 \mathrm{~K}$.

$\Delta \mathrm{G}^{0}$ can be obtained by using a thermodynamic cycle which includes one isodesmic reaction (4) and one dissociation process (5). In this thermodynamic cycle methyl arsonic acid was used as a reference molecule ${ }^{46}$ :

$$
\begin{aligned}
& \mathrm{HA}_{(a q)}+\mathrm{MeAsO}(\mathrm{OH}) \mathrm{O}_{(a q)}^{-} \stackrel{\Delta G_{4(a q)}^{0}}{\longrightarrow} A^{-}{ }_{(a q)}+\operatorname{MeAsO}(\mathrm{OH})_{2(a q)} \\
& \mathrm{H}_{2} \mathrm{O}_{(a q)}+\mathrm{MeAsO}(\mathrm{OH})_{2(a q)} \stackrel{\Delta G_{5(a q)}^{0}}{\longrightarrow} \mathrm{H}_{3} \mathrm{O}_{(a q)}^{+}+\mathrm{MeAsO}(\mathrm{OH}) \mathrm{O}_{(a q)}^{-}
\end{aligned}
$$


In aqueous solution the Gibbs free energy of dissociation of acid $H A, \Delta G^{0}$, can be written as a sum of Gibbs free energy changes of Eq. (4) and Eq. (5):

$$
\Delta G^{0}=\Delta G_{4(a q)}^{0}+\Delta G_{5(a q)}^{0}
$$

Using the experimental $p K a$ value, 4.1, for the reference molecule, ${ }^{54-56} \Delta G_{5(a q)}^{0}$ can be easily calculated using Eq. (3) as follow:

$\Delta G_{5(a q)}^{0}=1.36(4.1)+2.36=7.94(\mathrm{kcal} / \mathrm{mol})$

$\Delta G_{4(a q)}^{0}$ can be calculated using the proposed thermodynamic cycle which is shown in Fig. 1:

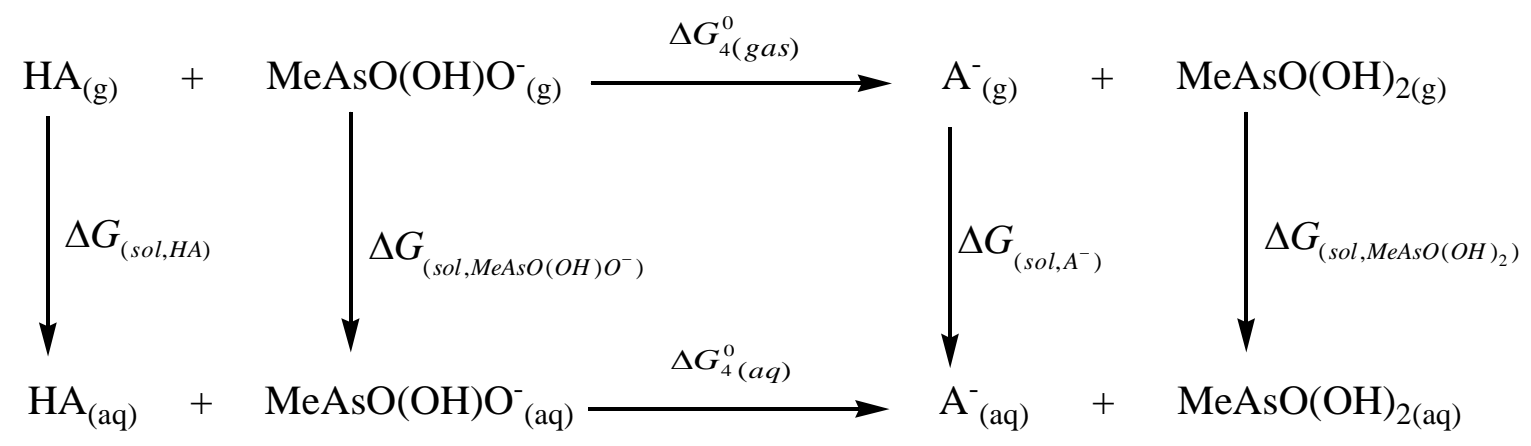

Fig. 1. Proposed thermodynamic cycle for calculation of $\Delta G_{4(a q)}^{0}$

From the thermodynamic cycle shown in Fig. $1, \Delta G_{4(a q)}^{0}$ can be written as the sum of $\Delta G_{4(g a s)}^{0}$ and $\Delta \Delta G^{0}{ }_{(\text {sol })}$, in which $\Delta G_{4(\text { gas })}^{0}$ and $\Delta \Delta G^{0}{ }_{(\text {sol })}$ are the gas-phase Gibbs free energy of reaction (4) and the net solvation energy of reaction (4), respectively:

$$
\begin{aligned}
& \Delta G_{4(a q)}^{0}=\Delta G_{4(\text { gas })}^{0}+\Delta \Delta G_{(\text {sol })}^{0} \\
& \Delta G_{4(g a s)}^{0}=\left[G_{\left(g a s, A^{-}\right)}^{0}+G_{\left(g a s, \mathrm{MeAsO}(\mathrm{OH})_{2}\right.}^{0}\right]-\left[G_{(\mathrm{gas}, \mathrm{HA})}^{0}+G_{\left(\text {gas }, \mathrm{MeAsO}(\mathrm{OH}) \mathrm{O}^{-}\right)}^{0}\right] \\
& \Delta \Delta G_{(\mathrm{sol})}^{0}=\left[\Delta G_{\left(\mathrm{sol}, \mathrm{A}^{-}\right)}^{0}+\Delta G_{\left(\mathrm{sol}, \mathrm{MeAsO}(\mathrm{OH})_{2}\right)}^{0}\right]-\left[\Delta G_{(\mathrm{sol}, \mathrm{HA})}^{0}+\Delta G_{\left(\mathrm{sol}, \mathrm{MeAsO}(\mathrm{OH}) \mathrm{O}^{-}\right)}^{0}\right]
\end{aligned}
$$

Finally, using the above thermodynamic cycle and equations, the pKa values were calculated using Eq. (10):

$$
\mathrm{pKa}=\mathrm{pKa}\left[\mathrm{MeAsO}(\mathrm{OH})_{2}\right]+\Delta G_{4(a q)}^{0} / 1.36
$$

\section{Results and Discussion}

The structure and nomenclature of the arsonic acids (1-25) selected for calculation are shown in Fig. 2. There is little data on pKa values of arsonic acids in the literature: those reported are in the range of $2.86-4.43 .^{54-56}$

In this study, we used the B3LYP method in combination with two different basis sets, 6$311++G(d, p)$ and $6-311++G(2 d, 2 p)$. Gibbs free energy changes of acid dissociation in the gas phase and computed pKa values with both selected basis sets are summarized in Table 2 . From these results it is concluded that the $6-311++G(2 d, 2 p)$ basis set gives reliable pka values with less error than that of those obtained when 6-311++G(d,p) is used. Compound 4 (4-nitronaphthyl-1-arsonic acid) is the strongest acid among those studied. Compound 2 (benzylarsonic acid) shows the weakest acidity with $\mathrm{pKa}=4.27$ because it is a non aromatic arsonic acid. Electron withdrawing groups such as halogen and 
nitro on the aromatic ring, especially in the ortho position, increase the acidity of the arsonic acid. In contrast, electron releasing groups on the aromatic ring, such as methyl, decrease the acidity.

Table 2. Changes in Gibbs free energy and pKa values of selected arsonic acids.

\begin{tabular}{|c|c|c|c|c|c|c|c|}
\hline \multirow[t]{2}{*}{ Comp. } & \multicolumn{2}{|c|}{$\Delta G_{(\text {gas })}^{0}(\mathrm{kcal} / \mathrm{mol})$} & \multicolumn{2}{|c|}{$\Delta G_{4(a q)}^{0}(\mathrm{kcal} / \mathrm{mol})$} & \multicolumn{2}{|c|}{ pKa(calc) } & \multirow{2}{*}{$\begin{array}{c}p K a \\
\text { (exp.) }\end{array}$} \\
\hline & $\begin{array}{c}\text { Basis set } \\
\mathbf{a}^{*}\end{array}$ & $\begin{array}{c}\text { Basis set } \\
\mathbf{b}^{*}\end{array}$ & $\begin{array}{c}\text { Basis set } \\
\text { a }\end{array}$ & $\begin{array}{c}\text { Basis set } \\
\text { b }\end{array}$ & $\begin{array}{c}\text { Basis set } \\
\text { a }\end{array}$ & $\begin{array}{c}\text { Basis set } \\
\text { b }\end{array}$ & \\
\hline 1 & 325.4 & 327.1 & -1.62 & -1.03 & 2.91 & 3.34 & 3.47 \\
\hline 2 & 326.7 & 328.2 & -0.19 & 0.23 & 3.96 & 4.27 & 4.43 \\
\hline 3 & 324.1 & 325.5 & -2.89 & -1.70 & 1.98 & 2.85 & - \\
\hline 4 & 314.2 & 315.8 & -3.95 & -3.21 & 1.19 & 1.74 & - \\
\hline 5 & 327.2 & 328.5 & -1.60 & -0.55 & 2.92 & 3.70 & - \\
\hline 6 & 326.5 & 327.9 & -0.71 & -0.99 & 3.58 & 3.38 & 3.82 \\
\hline 7 & 325.9 & 327.8 & -1.66 & -0.86 & 2.88 & 3.47 & 3.82 \\
\hline 8 & 324.6 & 325.9 & -3.74 & -3.07 & 1.35 & 1.84 & - \\
\hline 9 & 320.8 & 322.6 & -2.93 & -1.87 & 1.95 & 2.72 & - \\
\hline 10 & 322.5 & 323.8 & -3.46 & -2.40 & 1.55 & 2.33 & - \\
\hline 11 & 315.3 & 317.3 & -3.40 & -2.00 & 1.60 & 2.63 & 2.86 \\
\hline 12 & 330.0 & 330.9 & -2.63 & -1.32 & 2.17 & 3.13 & - \\
\hline 13 & 325.3 & 327.4 & -2.64 & -1.70 & 2.16 & 2.85 & - \\
\hline 14 & 329.4 & 330.4 & -1.35 & -0.29 & 3.11 & 3.89 & 4.08 \\
\hline 15 & 326.3 & 328.1 & -1.75 & -1.2 & 2.82 & 3.22 & - \\
\hline 16 & 322.9 & 323.9 & -2.33 & -2.12 & 2.39 & 2.54 & - \\
\hline 17 & 320.4 & 322.1 & -3.87 & -3.06 & 1.25 & 1.85 & - \\
\hline 18 & 323.7 & 325.2 & -2.03 & -1.39 & 2.61 & 3.08 & - \\
\hline 19 & 327.2 & 328.7 & -2.12 & -0.85 & 2.54 & 3.48 & - \\
\hline 20 & 326.0 & 327.2 & -1.75 & -1.93 & 2.81 & 2.68 & - \\
\hline 21 & 320.7 & 324.4 & -2.99 & -1.41 & 1.90 & 3.06 & - \\
\hline 22 & 326.4 & 327.9 & -1.91 & -0.37 & 2.69 & 3.83 & - \\
\hline 23 & 316.0 & 317.9 & -1.99 & -1.66 & 2.63 & 2.88 & 3.46 \\
\hline 24 & 330.0 & 330.8 & -2.60 & -0.91 & 2.19 & 3.43 & - \\
\hline 25 & 321.5 & 323.6 & -3.22 & -2.14 & 1.73 & 2.52 & - \\
\hline
\end{tabular}

${ }^{*}$ B3LYP level with two different basis sets a and b: 6-311++G(d,p) and 6-311++G(2d,2p), respectively. 


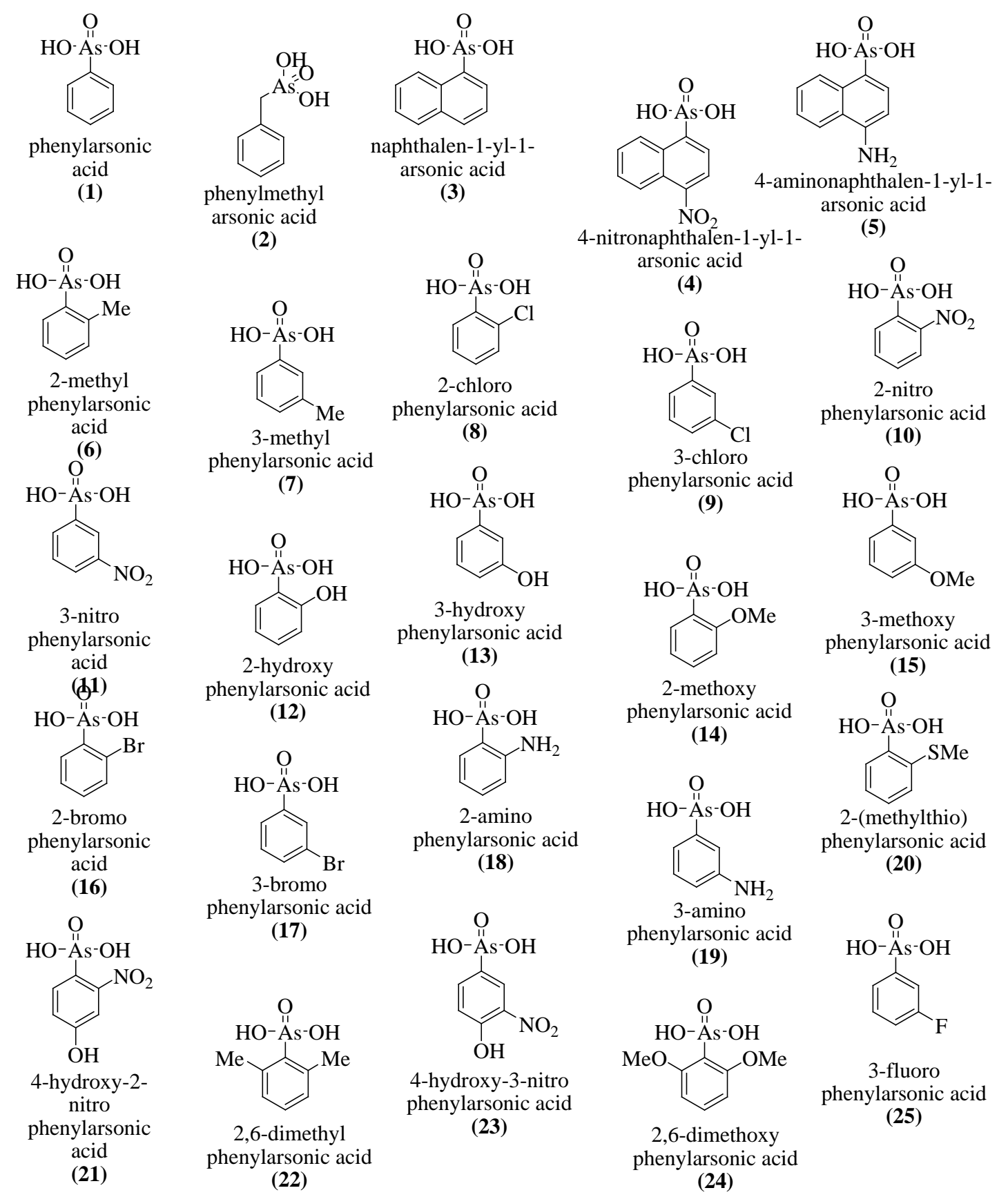

Fig. 2 Structures of investigated arsonic acids
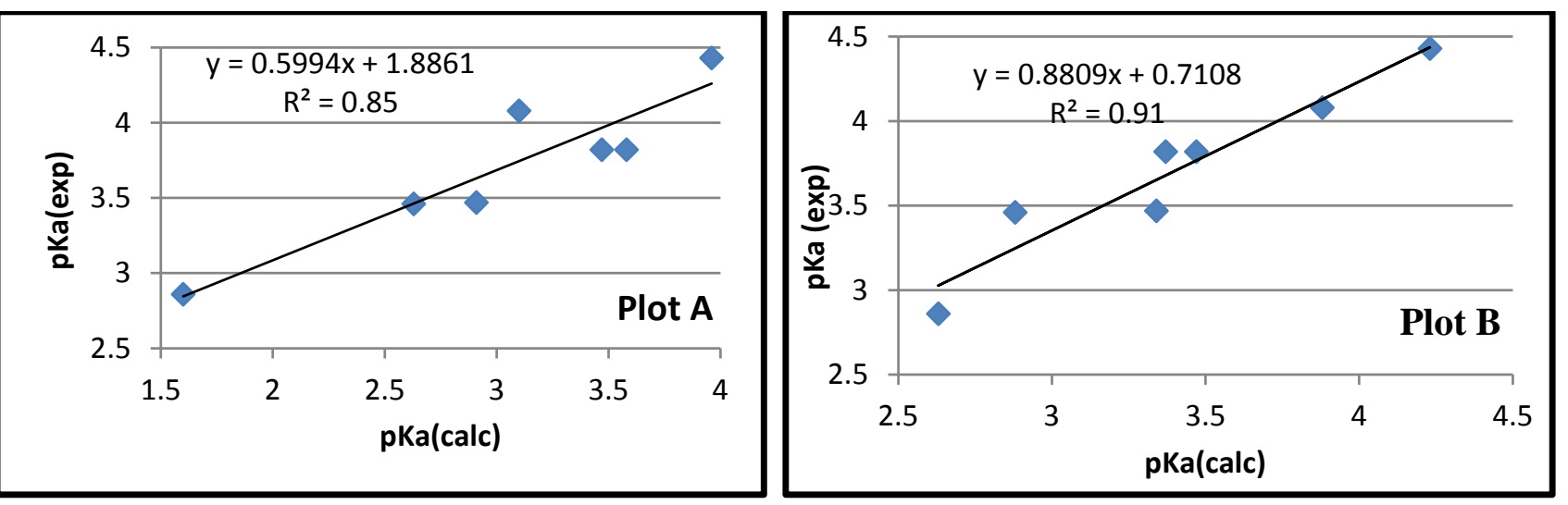

Fig. 3 Correlation between calculated and experimental $\mathrm{pKa}$ values of studied arsonic acids at (B3LYP/6-311++G(d,p)) level (plot A), and (B3LYP/6-311++G(2d,2p)) level (plot B). 
Comparison of our quantum mechanical computed pKa values with experimentally obtained literature values showed good correlation (Fig. 3): those using the $6-311++G(2 d, 2 p)$ basis sets gave better results $\left(R^{2}=0.91\right)$ than that using the $6-311++G(d, p)$ sets $\left(R^{2}=0.85\right)$. It is concluded that the computational level (B3LYP/6-311++G(2d,2p)) is appropriate to compute the relative pKa values of arsonic acid derivatives.

\section{Atomic Charges}

Charges on atoms in a molecule are not a quantum chemical observable property, but the atomic charge concept is a useful tool for the illustration of a variety of chemical phenomena. Determination of atomic charge in a molecule is accessible via several empirical and quantum mechanical methods. For each of the unionized arsonic acids, atomic polar tensor (APT) derived charges were calculated at B3LYP level of theory using 6-311++G(d,p) and 6-311++G(2d,2p) basis sets. For the acidic hydrogen $(\mathrm{H})$ and the entire arsonic acid group $\left(\mathrm{AsO}(\mathrm{OH})_{2}\right)$. Charges on the ionized oxygen $\left(\mathrm{O}^{-}\right)$and the charge on the whole corresponding conjugate anion, $\left(\mathrm{AsO}(\mathrm{OH}) \mathrm{O}^{-}\right)$, were also determined and are shown in Table 3. ${ }^{21,57-58}$ Good correlation between calculated pKa and the APT charges can be observed.

Table 3. Calculated APT charges for the studied arsonic acids.

\begin{tabular}{|c|c|c|c|c|c|c|c|c|}
\hline \multirow[t]{2}{*}{ Comp. } & \multicolumn{2}{|c|}{$Q M(H)$} & \multicolumn{2}{|c|}{$Q M\left(\mathrm{As}(\mathrm{OH})_{2}\right)$} & \multicolumn{2}{|c|}{$Q M\left(O^{-}\right)$} & \multicolumn{2}{|c|}{$Q M\left(\mathrm{AsO}(\mathrm{OH}) \mathrm{O}^{-}\right)$} \\
\hline & $\begin{array}{c}\text { Basis set } \\
\mathbf{a}^{*}\end{array}$ & $\begin{array}{c}\text { Basis set } \\
\mathbf{b}^{*}\end{array}$ & $\begin{array}{c}\text { Basis set } \\
\mathbf{a}\end{array}$ & $\begin{array}{c}\text { Basis set } \\
\text { b }\end{array}$ & $\begin{array}{c}\text { Basis set } \\
\mathbf{a}\end{array}$ & $\begin{array}{c}\text { Basis set } \\
\text { b }\end{array}$ & $\begin{array}{c}\text { Basis set } \\
\mathbf{a}\end{array}$ & $\begin{array}{c}\text { Basis set } \\
\text { b }\end{array}$ \\
\hline 1 & 0.399 & 0.389 & 0.267 & 0.278 & -1.491 & -1.490 & -0.608 & -0.599 \\
\hline 2 & 0.398 & 0.387 & 0.017 & 0.040 & -1.458 & -1.453 & -0.792 & -0.779 \\
\hline 3 & 0.397 & 0.387 & 0.232 & 0.241 & -1.493 & -1.499 & -0.599 & -0.565 \\
\hline 4 & 0.412 & 0.401 & 0.293 & 0.305 & -1.500 & -1.502 & -0.530 & -0.525 \\
\hline 5 & 0.392 & 0.382 & 0.281 & 0.285 & -1.527 & -1.525 & -0.566 & -0.561 \\
\hline 6 & 0.397 & 0.387 & 0.237 & 0.245 & -1.466 & -1.467 & -0.612 & -0.606 \\
\hline 7 & 0.396 & 0.384 & 0.285 & 0.291 & -1.485 & -1.482 & -0.606 & -0.597 \\
\hline 8 & 0.408 & 0.391 & 0.299 & 0.326 & -1.440 & -1.441 & -0.527 & -0.525 \\
\hline 9 & 0.398 & 0.388 & 0.315 & 0.326 & -1.481 & -1.480 & -0.575 & -0.568 \\
\hline 10 & 0.432 & 0.438 & 0.454 & 0.493 & -1.440 & -1.442 & -0.440 & -0.442 \\
\hline 11 & 0.399 & 0.391 & 0.342 & 0.342 & -1.475 & -1.474 & -0.545 & -0.550 \\
\hline 12 & 0.402 & 0.393 & 0.398 & 0.321 & -1.489 & -1.488 & -0.533 & -0.525 \\
\hline 13 & 0.408 & 0.394 & 0.270 & 0.282 & -1.475 & -1.473 & -0.587 & -0.581 \\
\hline 14 & 0.411 & 0.394 & 0.301 & 0.322 & -1.463 & -1.464 & -0.549 & -0.543 \\
\hline 15 & 0.408 & 0.395 & 0.270 & 0.283 & -1.474 & -1.439 & -0.589 & -0.561 \\
\hline 16 & 0.414 & 0.407 & 0.292 & 0.323 & -1.458 & -1.457 & -0.555 & -0.554 \\
\hline 17 & 0.412 & 0.401 & 0.281 & 0.291 & -1.472 & -1.471 & -0.575 & -0.566 \\
\hline 18 & 0.406 & 0.396 & 0.237 & 0.253 & -1.465 & -1.492 & -0.616 & -0.612 \\
\hline 19 & 0.398 & 0.384 & 0.288 & 0.297 & -1.484 & -1.482 & -0.601 & -0.594 \\
\hline 20 & 0.412 & 0.387 & 0.252 & 0.287 & -1.497 & -1.493 & -0.639 & -0.636 \\
\hline 21 & 0.390 & 0.396 & 0.469 & 0.520 & -1.482 & -1.483 & -0.421 & -0.419 \\
\hline 22 & 0.404 & 0.387 & 0.253 & 0.277 & -1.497 & -1.502 & -0.606 & -0.612 \\
\hline 23 & 0.394 & 0.396 & 0.353 & 0.338 & -1.475 & -1.476 & -0.529 & -0.524 \\
\hline 24 & 0.388 & 0.380 & 0.354 & 0.362 & -1.494 & -1.495 & -0.536 & -0.528 \\
\hline 25 & 0.409 & 0.396 & 0.282 & 0.294 & -1.465 & -1.464 & -0.574 & -0.569 \\
\hline
\end{tabular}

${ }^{*}$ B3LYP level with two different basis sets a and b: 6-311++G(d,p) and 6-311++G(2d,2p), respectively.

The results in Table 3 demonstrate that the delocalization of the negative charge of the deprotonated anion by the arsenic atom leads to an increase in the acidity of the corresponding arsonic acid. For example with the focus on data on Table 2 and Table 3 it could be concluded that as the delocalization of negative charge on $\left(\mathrm{AsO}(\mathrm{OH}) \mathrm{O}^{-}\right)$increased as a result an increase in acidity power observed. For example compounds 1, 2, 3 and 4 with respectively $-0.599,-0.799,-0.656$ and -0.525 negative charge on $\left(\mathrm{AsO}(\mathrm{OH}) \mathrm{O}^{-}\right)$and calculated pKa values of 3.34, 4.27, 2.85 and 1.74 verifies the direct relationship between acidity power and the amount of delocalization of negative charge on corresponding structure. Within four above mentioned structures, the more acidic compound 4 has the more delocalization value (lower negative charge on $\left(\mathrm{AsO}(\mathrm{OH}) \mathrm{O}^{-}\right)$. It should be note that this 
relationship between delocalized charge and pKa value dose not completely linear in all cases, because the delocalization value is not the only factor which could be affect the pKa value.

In this study, we also carried out quantitative analysis of the charge transfer from the $\mathrm{O}$ atom to the adjacent As atom using the NBO method. Fig. 4 shows the selected charges on selected arsonic acids. As shown in Fig. 4, in the neutral molecule the charge on the arsenic atom is more positive than that in the corresponding anion. For instance, the positive charge on the arsenic atom for the neutral molecules and (corresponding anions) of compounds 8 and 24 are 2.377 (2.356), and 2.380 (2.356), respectively. These data indicate that charge transfer occurs from the oxygen atom to arsenic during the deprotonation process.

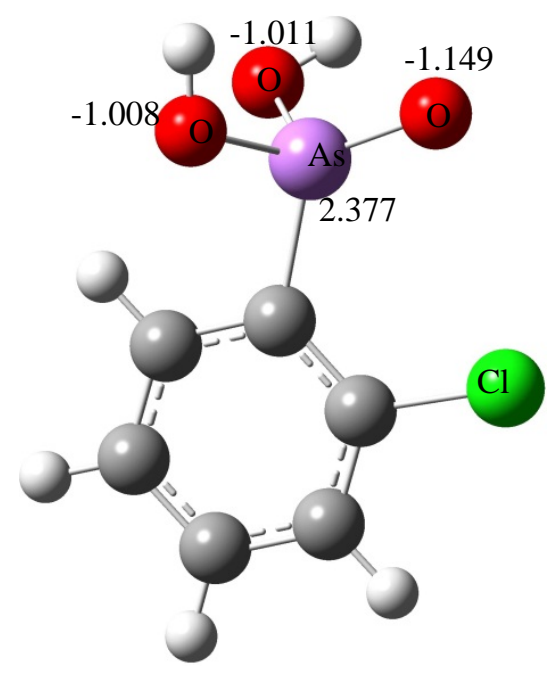

8a

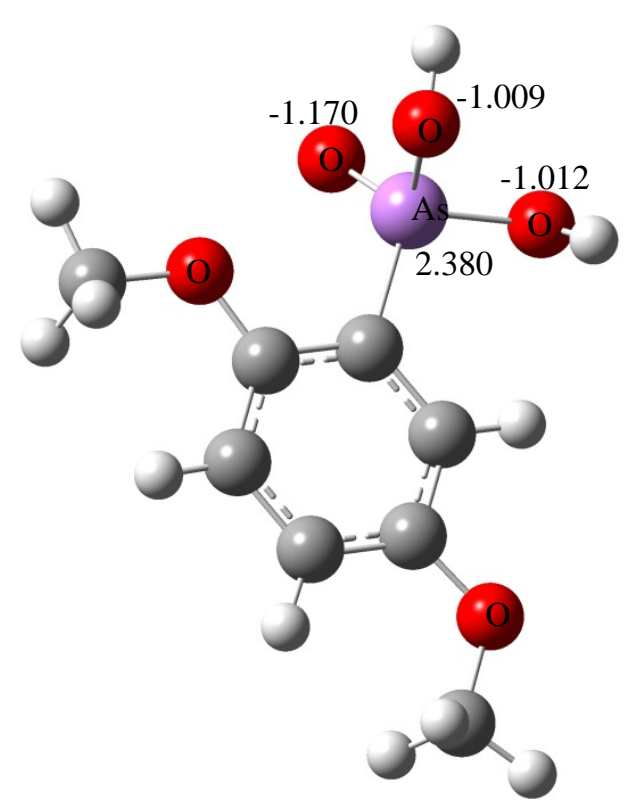

24a

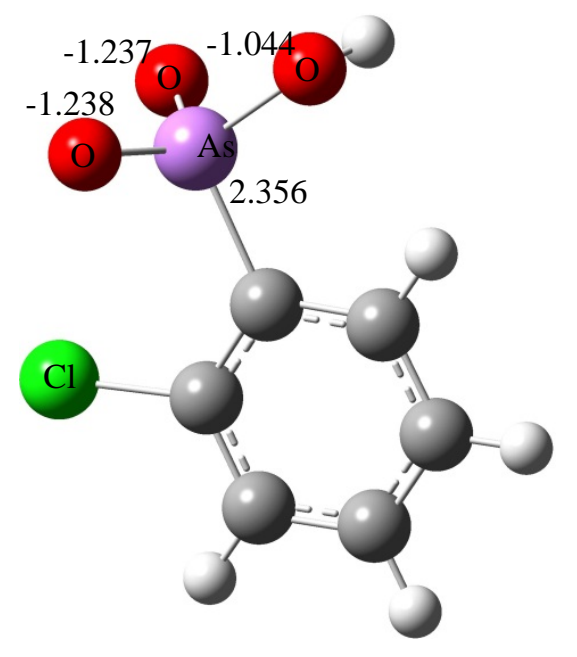

8b

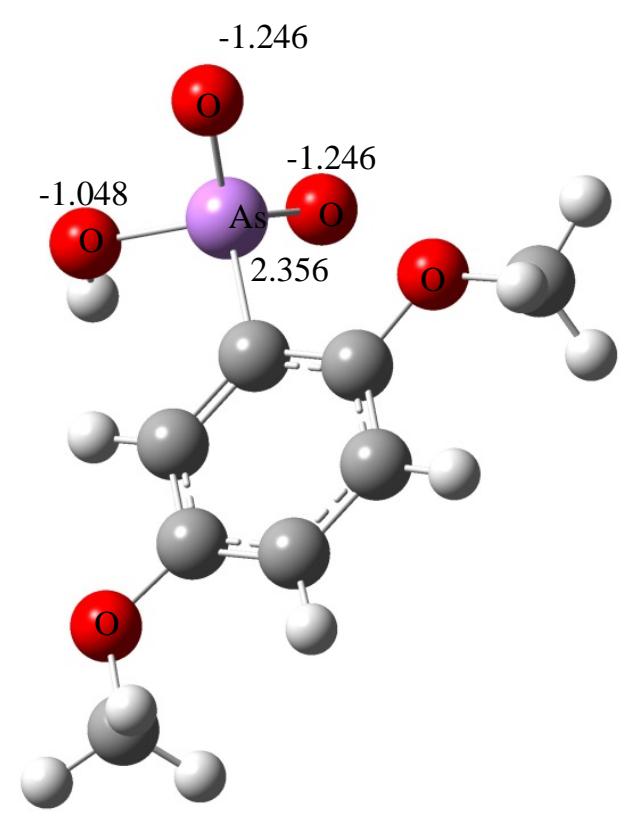

24b

Fig. 4 Natural Bond Orbital (NBO) charges on oxygen and arsenic in the neutral structures (8a and $\mathbf{2 4 a}$ ) and corresponding deprotonated structures (8b and $\mathbf{2 4 b}$ ). 


\section{Conclusions}

This work reports the calculation of the pka value of 25 arsonic acids in aqueous media using two different levels of theory. The results show a good linear relationship between experimental pKa values and the calculations, the average error being less than 0.8 and $0.3 \mathrm{pKa}$ units when the (B3LYP/6$311++G(d, p))$ and (B3LYP/6-311++G(2d,2p)) levels were used for calculations, respectively. The results confirm that the acid strength depends on the type of the substituent. Electron withdrawing groups attached to the arsonic acid lead to greater acidity than electron releasing groups because of their anion stabilizing capability. We also showed that the relative pKa values of arsonic acids can be calculated using (B3LYP/6-311++G(2d,2p)) level of theory with an acceptable accuracy.

\section{Acknowledgements}

Financial support of this work from the research council of the University of Guilan is gratefully appreciated. We also thank Professor Rolf H. Prager for proof reading of this article and Professor B. K. Nicholson from Waikato University for his suggestions and help.

\section{References}

1. Zirar S. B., Gibaud S., Camut A., Astier A. (2007) Pharmacokinetics and tissue distribution of the antileukaemic organoarsenicals arsthinol and melarsoprol in mice. J. Organometal. Chem., 692 (6) 1348-1352.

2. Dilda P. J., Hogg P. J. (2007) Arsenical-based cancer drugs. Cancer Treat. Rev., 33 (6) 542564.

3. Lehmann S., Bengtzen S., Paul A., Christensson B., Paul C. (2001) Effects of arsenic trioxide (As2O3) on leukemic cells from patients with non-M3 acute myelogenous leukemia: studies of cytotoxicity, apoptosis and the pattern of resistance. Eur. J. Haematol., 66 (6) 357-364.

4. Hu J., Fang J., Dong Y., Chan S. J., Chen Z. (2005) Arsenic in cancer therapy. Anti-Cancer Drugs., 16 (2) 119-127.

5. Saskai T., Yokagawa M., Wykoff D. E., Ritichie L. S. (1956) Asymptomatic amebiasis; treatment with atabrine in combination with carbarsone or chiniofon. United States Armed Forces medical journal, 7, 363-368.

6. Radke R. A. (1955) Ameboma of the intestine: an analysis of the disease as presented in 78 collected and 41 previously unreported cases. Ann. Intern. Med., 48 (5) 1048-1066.

7. Hoekenga M. T. (1951) A comparison of aureomycin and carbarsone in the treatment of intestinal amebiasis. Am. J. Trop. Med. Hyg., 31 (4) 423-425.

8. Ramadian D., Cline D. J., Bai S., Thorpe C., Schneider J. P. (2007) Effects of As(III) Binding on $\beta$-Hairpin Structure. J. Am. Chem. Soc., 129 (10) 2981-2988.

9. Spuches A. M., Kruszyna H. G., Rich A. M., Wilcox D. E. (2005) Thermodynamics of the As(III)-Thiol Interaction: Arsenite and Monomethylarsenite Complexes with Glutathione, Dihydrolipoic Acid, and Other Thiol Ligands. Inorg. Chem., 44 (8) 2964-2972.

10. Salerno M., Garnier-Suillerot A. (2003) Resistance to Arsenic- and Antimony-Based Drug. Bioinorg. Chem. And Applications, 1 (2) 189-198.

11. Lloyd N. C., Morgan H. W., Nicholson B. K., Ronimus R. S. (2005) The Composition of Ehrlich's Salvarsan: Resolution of a Century-Old Debate. Angew. Chem. Int. Ed., 44 (6) 941944.

12. Lloyd N. C., Morgan H. W., Nicholson B. K., Ronimus R. S. (2008) Substituted phenylarsonic acids; structures and spectroscopy. Journal of Organometallic Chemistry. 693 (14) 2443-2450.

13. Levander O. A. (1977) Biological effects of arsenic on plants and animals: Domestic animals: Phenylarsonic feed additives". Arsenic: Medical and Biological Effects of Environmental Pollutants. Washington DC: National Academies Press.149-151. 
14. Mcdougald L. R. (2005) Blackhead disease (histomoniasis) in poultry: a critical review. Avian Dis., 49 (4) 462-476.

15. Miller J. F. (1937) A New Reagent for the Detection of Cerium. Ind. Eng. Chem. Anal. Ed., 9 (4) 181-182.

16. Magill A. M., Yates B. F. (2004) An Assessment of Theoretical Protocols for Calculation of the pKa Values of the Prototype Imidazolium Cation. Aust. J. Chem., 57 (12) 1205-1210.

17. Magill A. M., Cavell K. J., Yates B. F. (2004) Basicity of nucleophilic carbenes in aqueous and nonaqueous solvents-theoretical predictions. J. Am. Chem. Soc., 126 (28) 8717-8724.

18. Fu Y., Liu L., Yu H-Z., Wang Y., Guo Q-X. (2005) Quantum-chemical predictions of absolute standard redox potentials of diverse organic molecules and free radicals in acetonitrile. J. Am. Chem. Soc., 127 (19) 7227-7234.

19. Namazian M., Halvani S. (2006) Calculations of pKa values of carboxylic acids in aqueous solution using density functional theory. J. Chem. Thermodynamics. 38 (12) 1495-1502.

20. Marie Toth A., Liptak M. D., Philips D. L., Shields G. C. (2001) Accurate relative pKa calculations for carboxylic acids using complete basis set and Gaussian-n models combined with continuum solvation methods. J. Chem. Phys., 114 (10) 4595-4606.

21. Kheirjou S., Abedin A., Fattahi A. (2012) Theoretical descriptors response to the calculations of the relative $\mathrm{pKa}$ values of some boronic acids in aqueous solution: A DFT study. Computational and Theoretical Chemistry, 1000, 1-5.

22. Ohno K., Kamiya N., Asakawa N., Inoune Y., Sakurai M. (2001) Application of an integrated MOZYME+DFT method to pKa calculations for proteins. Chem. Phys. Lett., 341 (3) 387-392.

23. Smith B. J., Radom L. (1991) Evaluation of accurate gas-phase acidities. J. Phys. Chem., 95 (26) 10549-10551.

24. Josefredo R., Plliego Jr. (2003) Thermodynamic cycles and the calculation of pKa. Chem. Phys. Lett., 367, 145-149.

25. Ding F., Smith J. M., Wang H. (2009) First-principles calculation of pKa values for organic acids in nonaqueous solution. J. Org. Chem., 74 (7) 2679-2691.

26. Silva C. O., Da silva E. C., Nascimento M. A. C. (2000) Ab Initio Calculations of Absolute pKa Values in Aqueous Solution II. Aliphatic Alcohols, Thiols, and Halogenated Carboxylic Acids. J. Phys. Chem., A, 104 (11) 2402-2409.

27. Delgado E. (2009) DFT calculation of pKa's for dimethoxypyrimidinylsalicylic based herbicides. Chemical Physics Letters, 471, 133-135.

28. Bryantsev V. S. (2013) Predicting the stability of aprotic solvents in Li-air batteries: pKa calculations of aliphatic $\mathrm{C}-\mathrm{H}$ acids in dimethyl sulfoxide. Chemical Physics Letters, 558, 4247.

29. Adam K. R. (2002) New Density Functional and Atoms in Molecules Method of Computing Relative pKa Values in Solution. J. Phys. Chem. A, 106 (49) 11963-11972.

30. Chen I-Jen., Alexander D., MacKerell Jr. (2000) Computation of the influence of chemical substitution on the pK a of pyridine using semiempirical and ab initio methods. Theoretical Chemistry Accounts, 103 (6) 483-494.

31. Klamt A., Eckert F. , Diedenhofen M. (2003) First Principles Calculations of Aqueous pKa Values for Organic and Inorganic Acids Using COSMO-RS Reveal an Inconsistency in the Slope of the pKa Scale. J. Phys. Chem. A, 107 (44) 9380-9386.

32. Ho J., Coote M. L. (2010) A universal approach for continuum solvent pK a calculations: are we there yet?. Theoretical Chemistry Accounts, 125 (1-2) 3-21.

33. BryantsevV. S., Diallo M. S., Goddard W. A. (2007) pKa Calculations of Aliphatic Amines, Diamines, and Aminoamides via Density Functional Theory with a Poisson-Boltzmann Continuum Solvent Model. J. Phys. Chem. A, 111 (20) 4422-4430.

34. Verdolino V., Cammi R., Munk B. H., Schlegel H. B. (2008) Calculation of pKa Values of Nucleobases and the Guanine Oxidation Products Guanidinohydantoin and Spiroiminodihydantoin using Density Functional Theory and a Polarizable Continuum Model. J. Phys. Chem. B, 112 (51) 16860-16873. 
35. Brown T. N., Mora-Diez N. (2006) Computational Determination of Aqueous pKa Values of Protonated Benzimidazoles (Part 1). J. Phys. Chem. B, 110 (18) 9270-9279.

36. Lu H., Chen X., Zhan C. G. (2007) First-Principles Calculation of pKa for Cocaine, Nicotine, Neurotransmitters, and Anilines in Aqueous Solution. J. Phys. Chem. B, 111 (35) 10599-10605.

37. Sutton C. C. R., Franks G. V., Silva G. (2012) First Principles pKa Calculations on Carboxylic Acids Using the SMD Solvation Model: Effect of Thermodynamic Cycle, Model Chemistry, and Explicit Solvent Molecules. J. Phys. Chem. B, 116 (39) 11999-12006.

38. Ali S. T., Karamat S., Kona J., Fabian W. M. F. (2010) Theoretical Prediction of pKa Values of Seleninic, Selenenic, Sulfinic, and Carboxylic Acids by Quantum-Chemical Methods. J. Phys. Chem. A, 114 (47) 12470-12478.

39. Rebollar-Zepeda A. M., Galano A. (2012) First principles calculations of pKa values of amines in aqueous solution: Application to neurotransmitters. International Journal of Quantum Chemistry, 112 (21) 3449-3460.

40. Sastre S., Casasnovas R., Muñoz F., Frau J. (2014) Isodesmic reaction for pK a calculations of common organic molecules. Highlights in Theoretical Chemistry, 5, 51-58.

41. Zeng Y., Qian H., Chen X., Li Z., Yu S., Xiao X. (2010) Thermodynamic Estimate of pKa Values of the Carboxylic Acids in Aqueous Solution with the Density Functional Theory. Chinese Journal of Chemistry, 28 (5) 727-733.

42. Silva C. O., da Silva E. C., Nascimento M. A. C. (2003) Comment on 'Thermodynamic cycles and the calculation of pKa'. Chem. Phys. Lett., 381, 244-245.

43. Najdian A., Shakourian-Fard M., Fattahi A. (2014) Cooperativity effects of intramolecular $\mathrm{OH}$...O interactions on pKa values of polyolalkyl sulfonic acids in the gas phase and solution: a density functional theory study. J. Phys. Org. Chem., 27 (7) 604-612.

44. Poliak P. (2014) The DFT calculations of pKa values of the cationic acids of aniline and pyridine derivatives in common solvents. Acta Chimica Slovaca, 7 (1) 25-30.

45. Chipman D. M. (2002) Computation of pKa from Dielectric Continuum Theory. J. Phys. Chem. A, 106 (32) 7413-7422.

46. Namazian M., Heidary H. (2003) Ab initio calculations of pKa values of some organic acids in aqueous solution. J. Mol. Struct., 620 (2) 257-263.

47. Scharnagl C., Raupp-Kossmann R. A. (2004) Solution pKa Values of the Green Fluorescent Protein Chromophore from Hybrid Quantum-Classical Calculations. J. Phys. Chem. B, 108 (1) 477- 489.

48. Liptak M. D., Shields G. C. (2001) Accurate pKa Calculations for Carboxylic Acids Using Complete Basis Set and Gaussian-n Models Combined with CPCM Continuum Solvation Methods. J. Am. Chem. Soc., 123 (30) 7314-7419.

49. Liptak M. D., Gross K. C., Seybold P. G., Feldgus S., Shields G. C. (2002) Absolute pKa determinations for substituted phenols. J. Am. Chem. Soc., 124 (22) 6421-6427.

50. Ding F., Smith J. M., Wang H. (2009) First-principles calculation of pKa values for organic acids in nonaqueous solution. J. Org. Chem., 74 (7) 2679-2691.

51. Namazian M., Siahrostami S., Noorbala M. R., Coote M. L. (2006) Calculation of two electron reduction potentials for some quinine derivatives in aqueous solution using Møller-Plesset perturbation theory. J. Mol. Struct.: Theochem., 759 (1) 245-247.

52. Namazian M., Kalantary-Fotooh F., Noorbala M. R., Searles D. J., Coote M. L. (2006) Møller Plesset perturbation theory calculations of the pKa values for a range of carboxylic acids. $J$. Mol. Struct.: Theochem, 758 (2-3) 275-278.

53. Schmidt M. W., Baldridge K. K., Boatz J. A., Elbert S. T., Gordon M. S., Jensen J. H., Koseki S., Matsunaga N., Nguyen K. A., Su S. J., Windus T. L., Dupuis M., Montgomery J. A. (1993) General Atomic and Molecular Electronic Structure System. J. Comput. Chem., 14 (11) 13471363.

54. National Research Council (1999) Arsenic in Drinking Water. Washington, DC: The National Academies Press.

55. Macintyre J. E. (1994) Dictionary of organometallic compounds, Chapman \& Hall, Vol 2. 
56. Aylett B. J. (1979) Organometallic Compounds The Main Group Elements Vol 1 Part II Chapman and Hall London. Ch 7, 390-507.

57. Gross K. C., Seybold P. G., Hadad C. M. (2002) Comparison of different atomic charge schemes for predicting pKavariations in substituted anilines and phenols. Int J Quantum Chem, 90 (1) 445-458.

58. Hollingsworth C. A., Seybold P. G., Hadad C. M. (2002) Substituent effects on the electronic structure and pKa of benzoic acid. Int. J. Quantum Chem., 90 (4-5) 1396-1403. 